\title{
Old Ways in a Changing Space: The Issue of Camel Pastoralism in Dhofar
}

\author{
Ali Tigani EIMahi* \\ Department of Archaeology, College of Arts and Social Sciences \\ Sultan Qaboos University, P.O. Box 42, Al-Khod 123 \\ Muscat, Sultanate of Oman
}

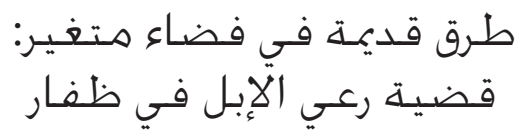

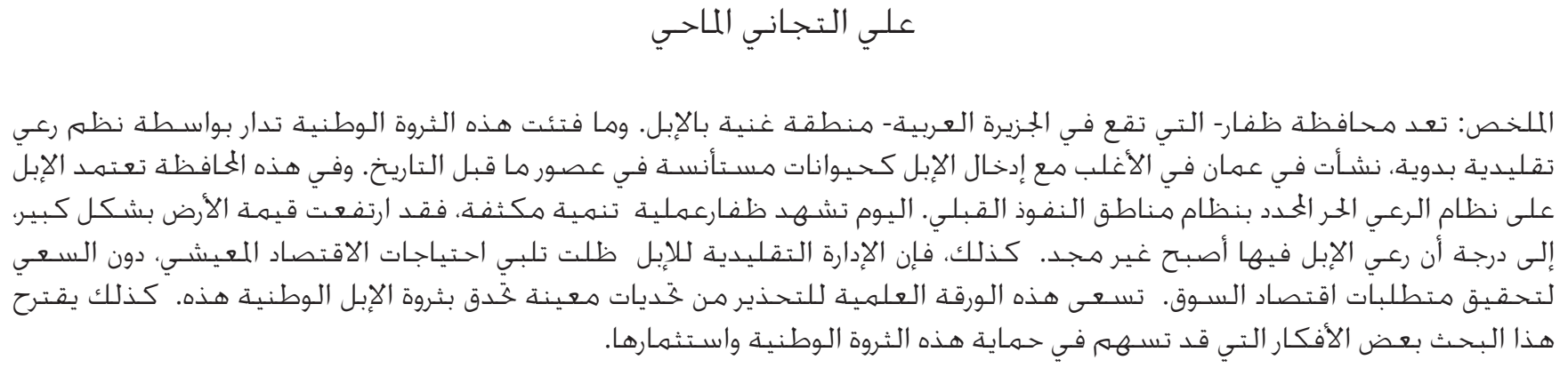

ABSTRACT: In the Arabian Peninsula, the Dhofar region is rich in camels. This national wealth has always been administered by traditional nomadic pastoral management, which must have evolved in Oman with the introduction of camels as domesticates in prehistoric times. In this region, camels have always depended on the free grazing system which is governed by tribal territoriality. Today, Dhofar is experiencing an extensive process of development. Land value has increased immensely, to the extent that it cannot be used for camel pastoralism. Furthermore, traditional camel management has always been directed to meet requirements of a subsistence economy. It has never managed to convert to the organization of political economy. This paper intends to raise the alarm that national wealth is endangered by certain challenges. The paper proposes certain ideas that might assist in safeguarding and investing in a national asset.

Keywords: Dhofar region, camel pastoralists, traditional camel management, subsistence economy, development, national wealth.

\section{Introduction}

This paper is the outcome of three years of ethnoarchaeological field investigations (2009-2011) carried out by the author among the traditional camel pastoralists in Dhofar region of the Sultanate of Oman (Map 1). The study intends to document the ways and methods of the camel pastoralists. In addition, the study is an aid to archaeological studies with possible explanations of prehistoric nomadic pastoralists' adaptation, camel management, movements, territoriality, diet etc. in that particular region.

The study was based on informal interviews with several elderly camel pastoralists in Dhofar. In addition, interviews were carried out with different staff members in the Ministry of Agriculture and Fisheries in Dhofar. Throughout the interviews and the author observations, it became unequivocal that a new reality poses certain challenges to traditional camel pastoralism in Dhofar. Consequently, this paper is an attempt to emphasize the urgency of a situation, which needs to be addressed earnestly and immediately.

Change is a primary and inevitable process in life's dynamics and human societies can never be static and cannot be eternally invariable. Although change is predestined in human societies, it varies in degree, magnitude and tempo.
Change can take place through several agents, some are designed by the society (e.g. adaptation), while others are forced upon human societies. Nonetheless, what is dramatic in any process of change is its tempo. Therefore, sudden and rapid change or changes are usually dramatic and result in various unpredictable consequences.

Progressive change has come to traditional camel pastoralism in Dhofar through the development of the oil industry. The Sultanate of Oman has directed its resources of oil to achieve sustainable development. Consequently, the Dhofar region has a share in this development, which has brought change on a large scale to all aspects of life. This has resulted in unavoidable changes for camel pastoralists in the region and as a result camel nomadic pastoralism is facing serious challenges that will eventually eradicate this traditional way of life, culture, and economy (Plate 1). Traditional camel nomadic pastoralism proved unable to cope with the progressive development that has recently taken place in the region. Although development has contributed significantly to the improvement and conditions of the pastoralists and their animals, they maintained their old ways. Up to the present time, camels in Dhofar are managed and put to economically profitable use in accordance with ancestral 


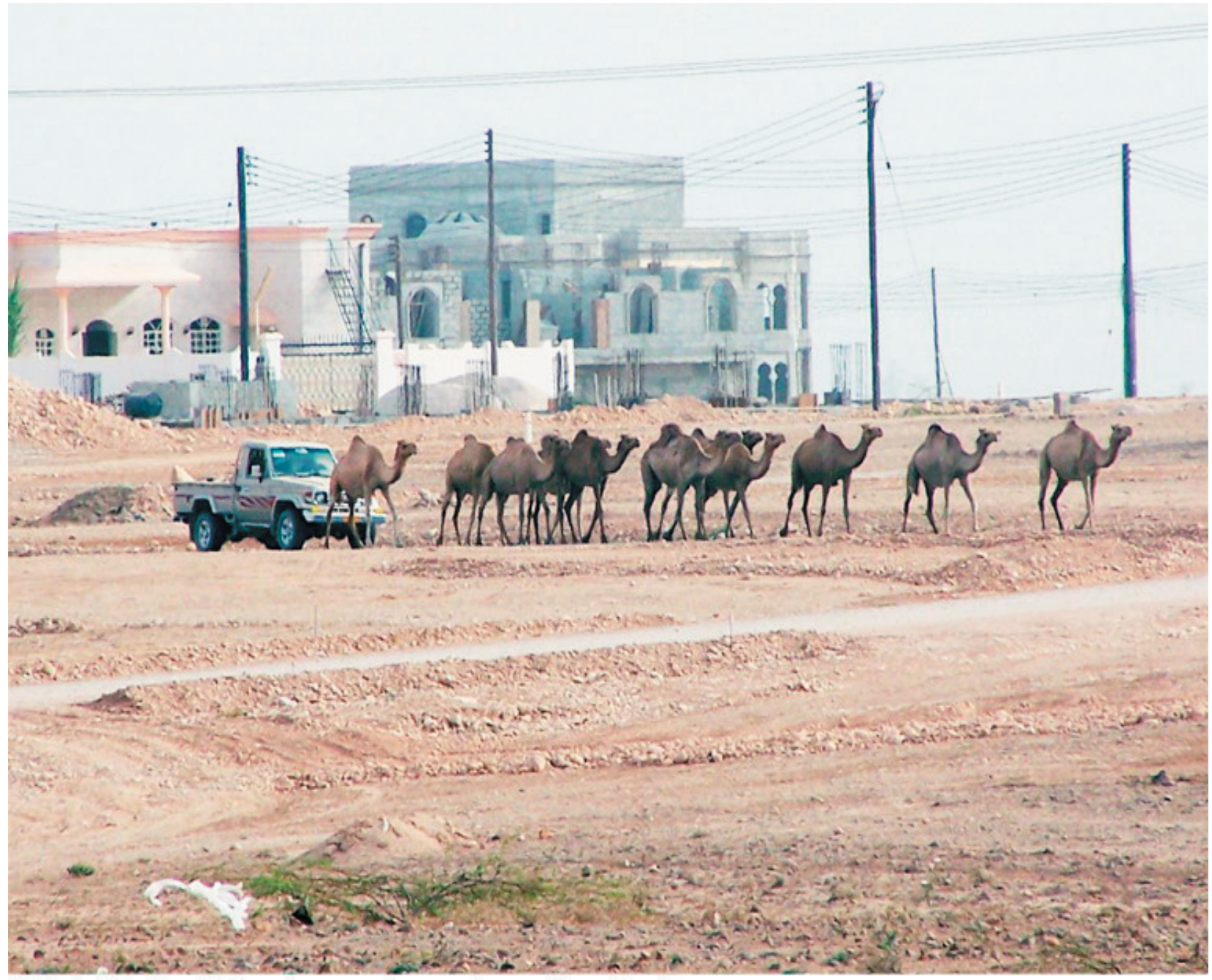

Plate 1. Dhofar: A changing space for camel nomadic pastoralism.

ways. It has become a deeply rooted culture in a time and space where patterns of life are changing. The situation is an impediment to a national wealth that demands a call for special efforts and dedication.

This paper casts light on the challenges that face camel nomadic pastoralism and camel production in Dhofar region. The paper brings the issue of camel nomadic pastoralism into focus and addresses it through pasture decrease and deforestation in the region, traditional camel management and cost, camel economy and development and land value.

The paper also presents an outline of a proposed strategy to deal with this issue. In doing so, the paper looks into camel nomadic pastoralism as a way of life and an integral part of Oman's cultural heritage, the changes and challenges brought by development and the present situation in the light of future prospects. Finally the author proposes certain ideas that might contribute tom finding solutions. However, it would be more useful to have a glance at camel nomadic pastoralism in Dhofar before proceeding with the camel current situation in this particular part of Oman.

\section{Traditional Camel Nomadic Pastoralism}

Throughout history Dhofar has gained fame and wealth as an ancient region in southern Arabia (Map 1). It secured a notable position in the history of southern Arabia. Its fame extended from the classical times of ancient Greece and Romans to Medieval times. Its geographical location in the Arabian Peninsula, and production of frankincense and camels for trade across the vast desert of Arabia have contributed prodigiously to its position and fame in old and Medieval Arabia. Therefore, camels as a mean of transport and commerce have participated effectively in the prosperity of Dhofar.

On the other hand, the geography and the weather have always been to Dhofar's advantage. The monsoon winds have contributed in creating an ecoregion of dazzle fog conditions and rain. This monsoon climate gives a new lease of a seasonal life characterized by lush vegetation and woodland. A distinct wet season, known as Al-Khareef, envelops Dhofar's landscape during July to September. The Khareeef encouraged cyclical movements and later transhumant seasonal movements (Plate 2). This ecological setting has furnished camel pastoralists with 


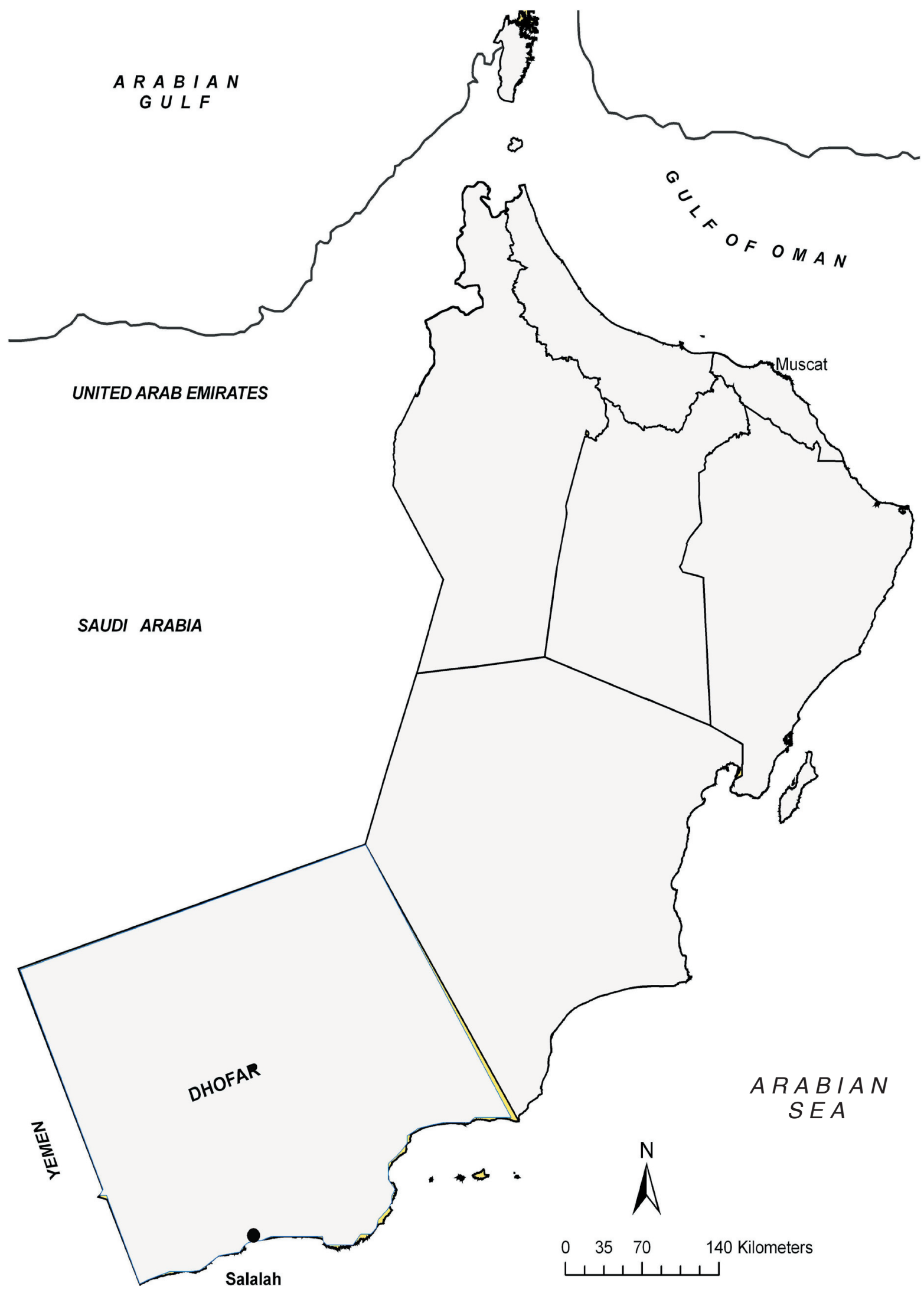

Map 1. Dhofar: study area. 


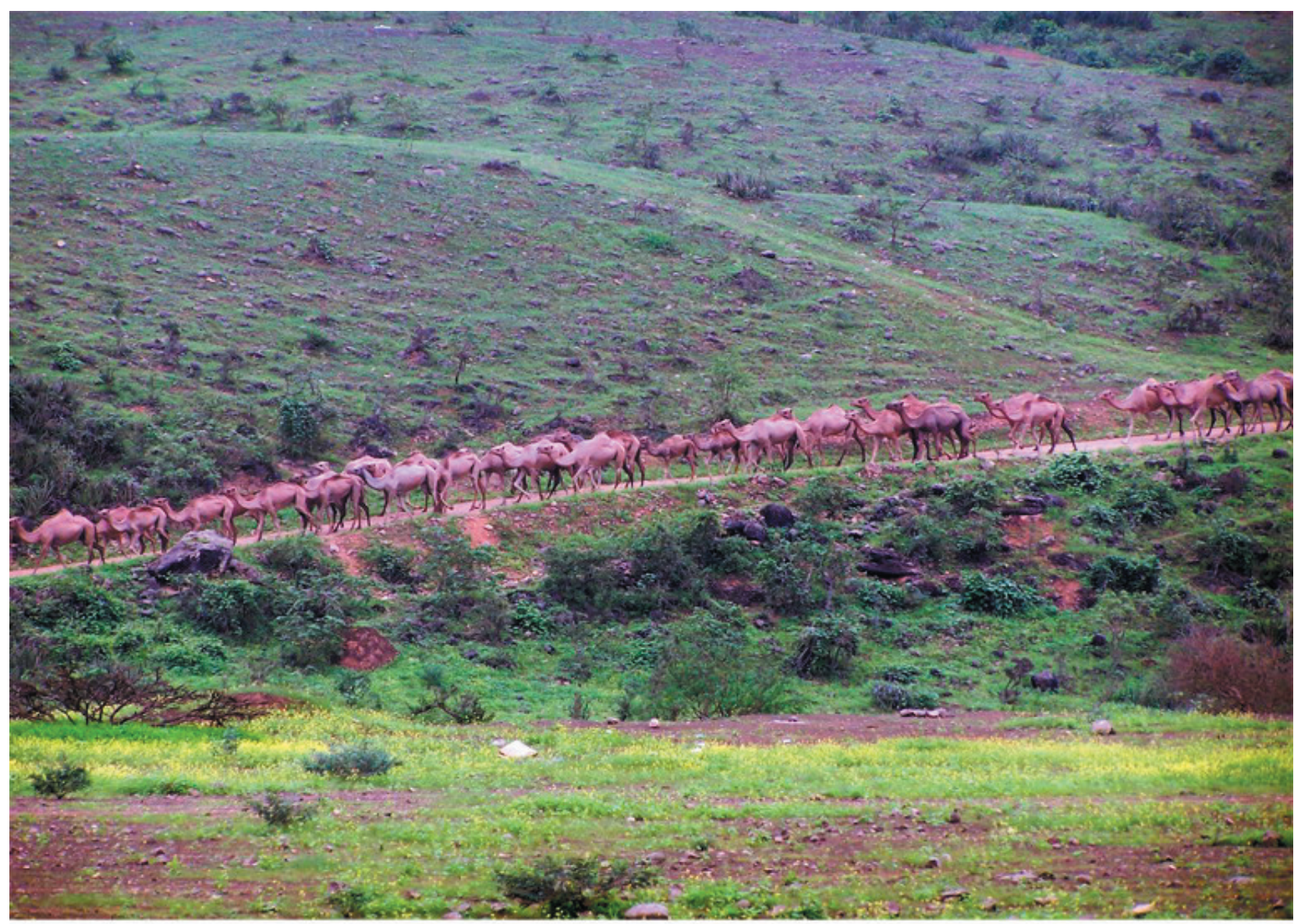

Plate 2. Seasonal ecological conditions and transhumant movements.

favourable conditions to nurture and increase their animal herds.

The history of camel nomadic pastoralism in Oman is not yet known. It is believed that camels were first domesticated around 3000 B.C. in Iran (Zarins, 1989). Therefore, it is possible to assume that camel pastoralists existed in Oman sometime after 3000 B.C. Camel nomadic pastoralism must have been a significant evolution in prehistoric societies' dynamism and adaptation. Camel pastoralism, on the other hand, is not just a group of people with an economy based on camel husbandry. It is certainly far more than this. It was a way of life, a culture, an economy and an adaptation. Odum (1971) suggests that the process of domestication is a two-way relationship in which both the domesticator and the domesticated are influenced by each other. This two-way relation is well exhibited in camel pastoralism. For the pastoralists, camels have always been their means of survival, pride, wealth, fascination and passion. Consequently, and from an unknown length of time camel pastoralists have developed a profound camel cultural dogma.

Up to this time, Dhofar is the largest camel producing region in the Sultanate of Oman. The latest statistics for 2004/2005 indicate that there are 53,527 camels in Dhofar. These animals are owned by most of the Dhofari tribes.
In the past, camel herders adopted a pattern of life based on cyclical movement that uses short stops in localities of favourable pasture. They recognize no fixed point for settlement. In effect, mobility was security.

Today, and under the improved conditions of development, they practice a transhumant seasonal movement system that recognizes seasonal settlements in particular locations in response to the seasonal ecological conditions. This is again attributed and explained by the improved conditions brought to the region by development (Plate 3). In fact, security has improved, life is much easier for the pastoralists, and they possess much more cultural material and built houses. This is another type of camel pastoralism.

\section{The Crisis of Pastoralism}

The issue of nomadic camel pastoralism has been a significant issue in anthropological, agricultural, economic studies and in governments' policies across the world. Africa and Asia have been the setting for many studies that deal with the nomadic camel pastoralists and the camel crisis, its economy, culture and future prospects (Kakar et al., 2011; Brey and Faye, 2005; Köhler-Rollefsonm, 2003; Kaufmann and Binder, 2002; Hüelsebusch and Kaufmann, 2002; Tefera and Gebreah, 2001; Beck, 1998; Abbas et 


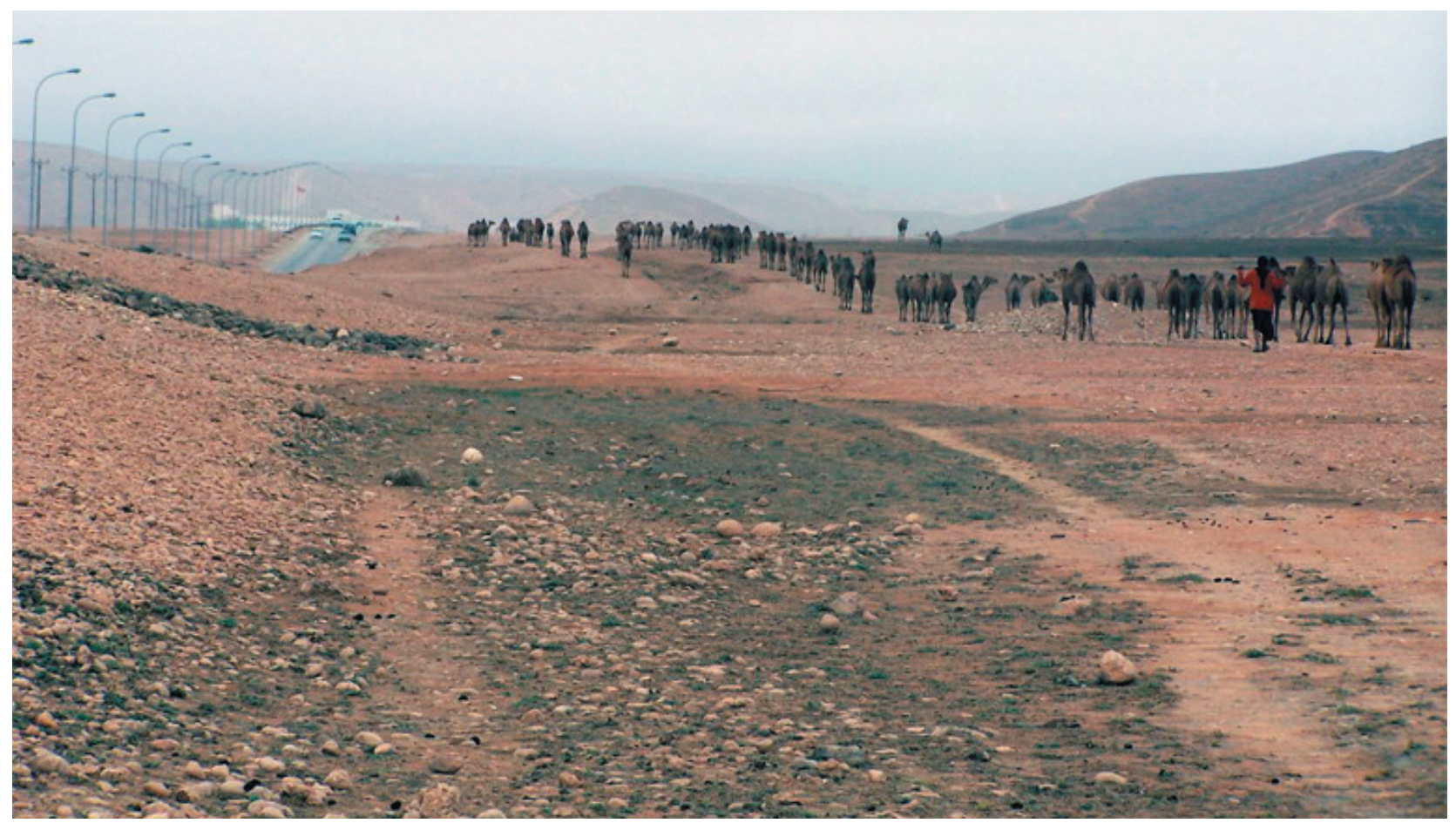

Plate 3. Development and camel nomadic pastoralism.

al., 1992; Köhler-Rollefson et al., 1991; Abdullahi, 1990; Salih, 1988; Sperling, 1987; Shepherd, 1983; Gilbert, 1983; Gauthier-Pilters and Dagg, 1981; Dyson-Hudson and Dyson-Hudson, 1980; Ibrahim, 1978; Birks, 1978; Spooner, 1975).

Up to the present, the camel crisis and pastoralists position haunt many developing countries in the southern hemisphere and concern researchers, policy makers, local governments and administrations. The issue is multi-faced and combined with the complexity of socio-economic and cultural dynamics of pastoral societies, the stress of ecological conditions and the vegetation cover.

In Oman, there are limited studies that deal with camel pastoralism. Janzen (1986) was almost the first to address the nomadic pastoralists in Oman. Later, Chatty (1990, 1994, 1996, and 2002) and Chatty et al. (1991) addressed various aspects of pastoralists in relation to their mobility, development and planning in Oman, and social and economic change. Furthermore, Chatty (2002) discussed the mobile nomadic pastoralists and the new dawn of multinational oil exploration in Oman. She (ibid.) indicates that although the nomadic pastoralists of the central desert have received health and social services, education, etc., they were not forced to settle or change their way of life. It can be added here that the government of Oman has extended this policy all over the country. In other words, no mobile pastoralists were asked or forced to settle down or change their ways (Plate 4).

Among all these issues, the current crisis of camel nomadic pastoralism in Dhofar was not addressed. The camel crisis in Dhofar emerged in the late nineties. This happened in 1993-4 when Traverse Morgan on behalf of the
Higher Committee of Towns Planning executed a study in Dhofar [Report by the General Directorate of Agriculture, Fisheries and Animal Wealth in Dhofar (March, 1998)]. Consequently, the camel issue came into focus. Traverse Morgan was commissioned to investigate the plant cover deterioration in Dhofar. Therefore, it is the deterioration of the plant cover and soil in Dhofar that brought out the camel pastoralism role and camels. Interestingly, the study by Traverse Morgan in 1993-4 suggested as a solution to the deteriorating floral and soil conditions, the reduction of animal numbers in Dhofar [(Report by the General Directorate of Agriculture, Fisheries and Animal Wealth in Dhofar (March, 1998)]. After almost five years, the General Directorate of Agriculture, Fisheries and Animal Wealth in Dhofar conducted a study on the impact of camels on the plant cover and the soil. The General Directorate took Wadi Nahiz and Grzaz as a case study. The report by the General Directorate of Agriculture, Fisheries and Animal Wealth in Dhofar (March, 1998) recommends the following procedures:

i. The number of camels must be carefully recorded.

ii. The reduction of camel population through helping those who wants to completely get rid of their camels and by offering attractive prices.

iii. This policy is to be carried out until the present camel population is reduced to 80 or $90 \%$.

iv. Precautions must be taken to avoid another increase in camel population.

These procedures were also stated in another report by the General Directorate of Agriculture, Fisheries and Animal Wealth in Dhofar (February, 1998). The 


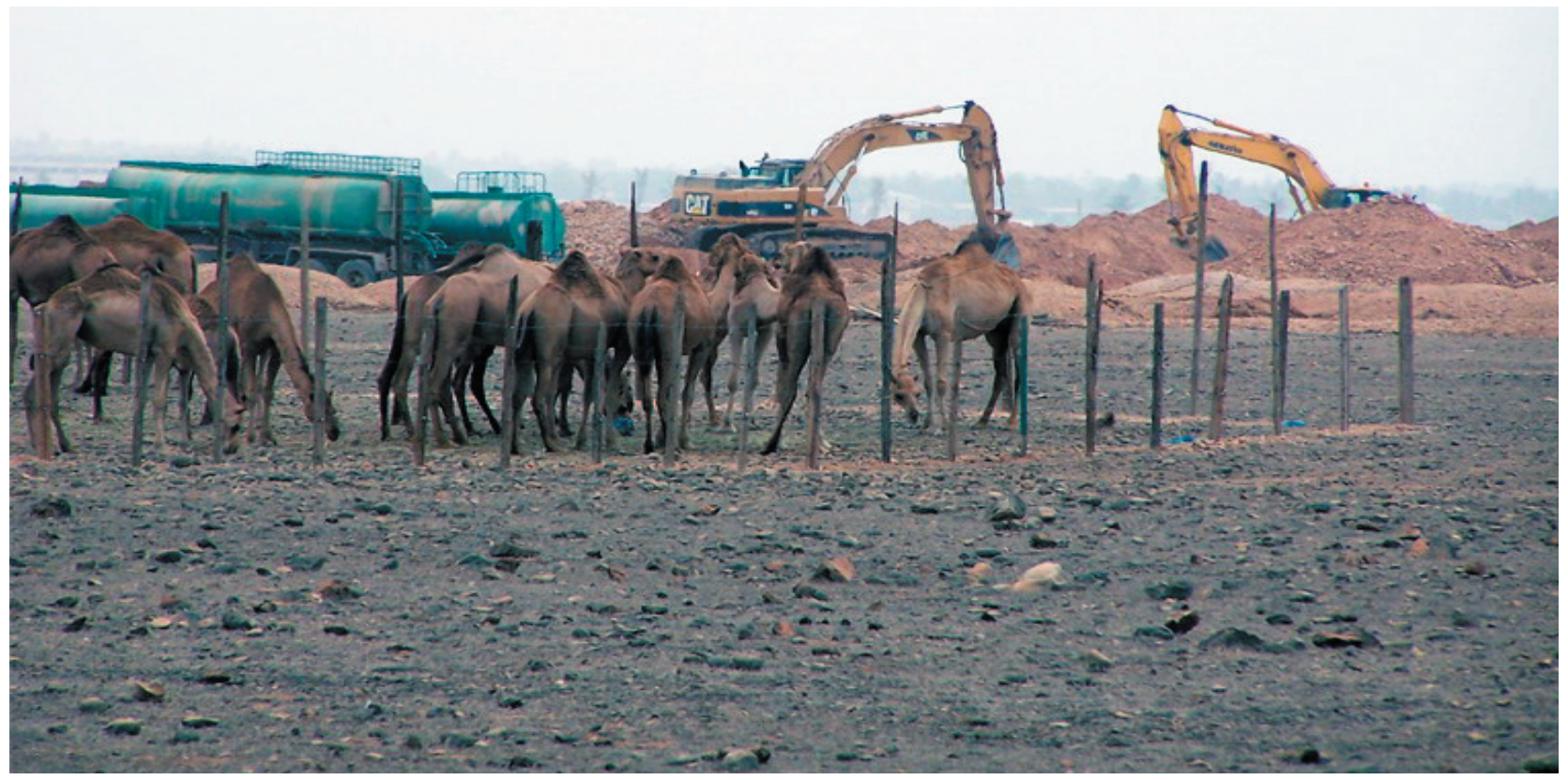

Plate 4. A changing space for camel nomadic pastoralism.

General Directorate's report rationalizes the procedures mentioned above on basis of the conclusions made by the study carried out by the Australian GR Min 1991. This study warns that the continuous absence of any interference by the Dhofar government will eventually lead to the complete disappearance of the plant and tree cover in Dhofar within 20 to 30 years. The policy of camel reduction in Dhofar was also supported by the study by Traverse Morgan (1993-4). This study affirms $90 \%$ of the natural pasture in Dhofar is in poor condition and continuously deteriorating [Report by the General Directorate of Agriculture, Fisheries and Animal Wealth in Dhofar (February, 1998)].

It is unquestionable that development as a means of progress necessitates change and sometimes brings to the forefront unpredictable and contingent consequences. By the early seventies, promotion of veterinary services in the region had successfully controlled significant animal diseases and parasites. Consequently, the valuable veterinary services have advanced animal health conditions, which eventually facilitated the increase of animal numbers. This has taken place in a society that looks up to camels with great affection and admiration. The belief among the pastoralists in Dhofar is typical among pastoralists worldwide; larger herd of animals reflects the owner's expanding and prestigious status. Therefore, camel owners attempt to increase the size of their herds. For the camel owners status is manifested and displayed by the animals' quantity and quality and not their economic asset. This situation marked an increase in animal numbers and eventually affected the pastures' carrying capacity.

Overgrazing led to the decrease of natural pasture in the region (Plate 5). In other words, the carrying capacity of the region can no longer sustain the continuously increasing numbers of camels. With less natural pasture, camel pastoralists have been forced to seek another source as a supplement for their animals. Today, camel pastoralists are dependent on two commodities for feeding their camels: grass (commercial fodder) and camel food (concentrates). Grass is cultivated by certain companies and sold in bales. As for the camel food (concentrates), it is a mixture of several ingredients such as the bran of wheat, rice, yellow maize and sugar molasses, salt, etc. This new commodity is widely commercialized among camel herders, who have eventually become dependent on it for feeding their animals. Hence, camel herding becomes costly. In reality, a new costly feeding strategy has been forced on the camel pastoralists in Dhofar.

\section{The Impact on the Camel Economy}

Today, camel husbandry turns out to be expensive in the Dhofar region. Under the current conditions their maintenance turns out to be demanding. The factors responsible for this situation can be summed up in the following:

First, natural pastures are too limited to serve the needs of the increasing camel population in Dhofar. As mentioned previously, this situation has led the camel pastoralists to be dependent more and more on commercial fodder and camel feed (concentrates). This is completely unconventional for pastoralism as a way of life. However, Dhofari camel pastoralists found themselves gradually obligated to turn to purchase commercial fodder and camel food (concentrates). This has been a turning point in the economy of camel nomadic pastoralism. One of the elderly informants Ahmed bin Mohamed bin Salim Al Mashani, a well-experienced camel pastoralist who has 


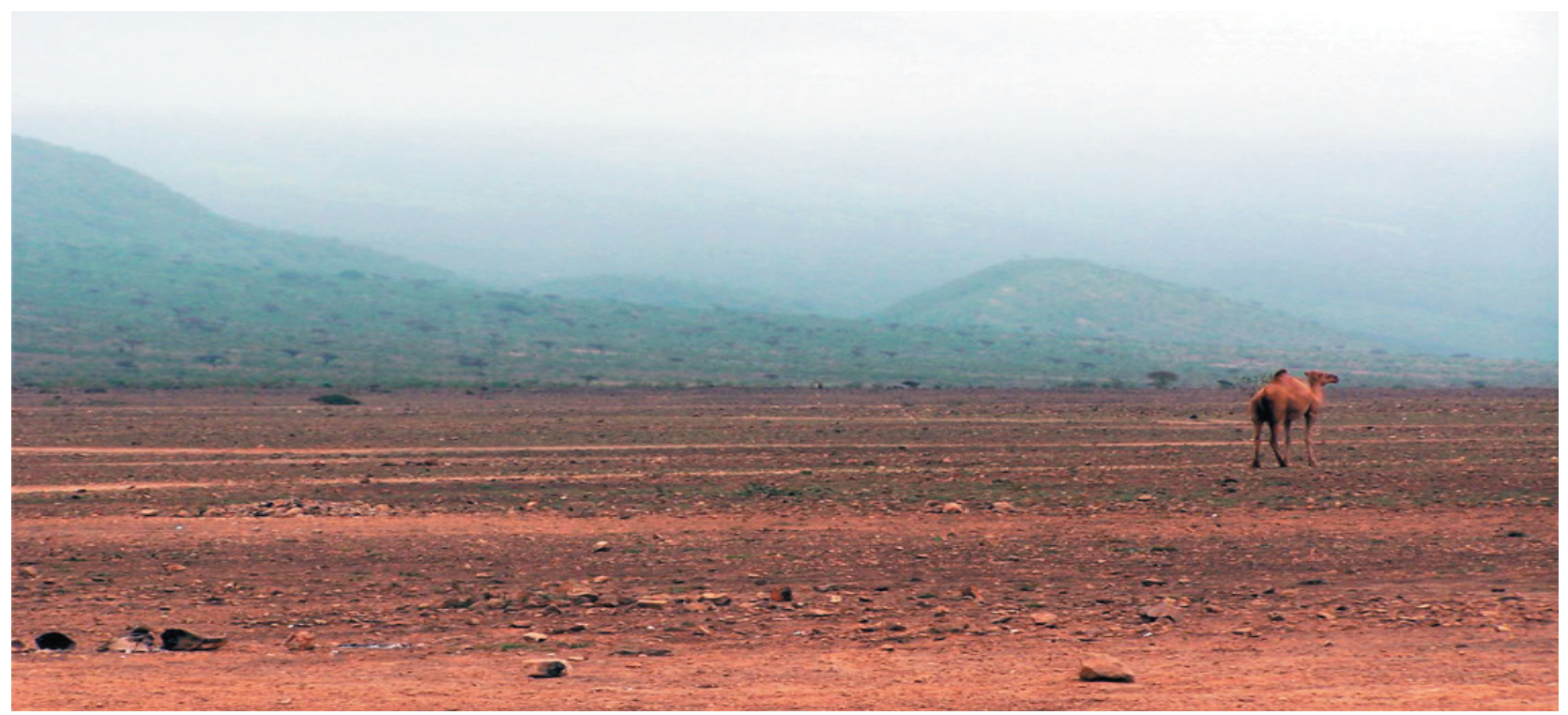

Plate 5. Overgrazing hits natural pastures.

30 camels reported their monthly expenses (Table 1a). Another camel herder from same tribal group; Salim AliAl Mashani has 50 camels and states his monthly expenses (Table 1b).

Another informant, Salim Al Shahri reported the sums he spends monthly on his fifty female camels. Table 2 summarizes his monthly expenses.

In Dhofar, camel owners have limited income. All the camel owners who were interviewed claim that these expenses are becoming a financial burden on the whole family's economy. They stress that camels are becoming a true burden and conditions cannot be compared with the

Table 1a. The cost of camel feeding per month (Camel owner 1).

\begin{tabular}{llcc}
\hline $\begin{array}{l}\text { No. of } \\
\text { Camels }\end{array}$ & Item & $\begin{array}{c}\text { Cost per Month } \\
\text { (in Omani Riyal) }\end{array}$ & $\begin{array}{c}\text { Equivalent } \\
\text { (in US \$) }\end{array}$ \\
\hline 30 & $\begin{array}{l}\text { Commercial fodder } \\
\text { (hashish) } \\
\text { Camel food } \\
\text { (concentrates) }\end{array}$ & ca. 180 & ca. 466 \\
\hline Total & ca. 400 & ca.1036 \\
\hline
\end{tabular}

Table 1b. The cost of camel feeding per month (Camel owner 2).

\begin{tabular}{llcc}
\hline $\begin{array}{l}\text { No. of } \\
\text { Camels }\end{array}$ & Item & $\begin{array}{c}\text { Cost per Month } \\
\text { (in Omani Riyal) }\end{array}$ & $\begin{array}{c}\text { Equivalent } \\
\text { (in US \$) }\end{array}$ \\
\hline 50 & $\begin{array}{l}\text { Commercial fodder } \\
\text { (hashish) } \\
\text { Camel food } \\
\text { (concentrates) }\end{array}$ & ca. 300 & ca.777 \\
\hline Total & ca. 500 & ca. 1295 \\
\hline
\end{tabular}

times when there was enough pasture. In fact, nomadic pastoralism exploiting pasture through a free grazing system is an economical profession and has a costeffective economy.

Second, camel nomadic pastoralism renders limited economic returns at the present time. Generally, the demand for camel milk and meat in the Sultanate as a whole is very limited when compared to the other products available in the market and consumed. Milk, for example has a very limited demand in the local markets. This situation is attributed to the fact that camel milk is not commercially marketed to consumers. As for camel meat, the local markets are flooded with imported meat from various countries to the extent that it has influenced the Omani cuisine. As for the price in local markets, camel meat cannot compete with other imported beef, sheep and goat meat. A simple statistical indication can possibly illustrate this fact (Tables 3, 4, 5 and 6) (personal communication in 2010 and 2011 with Dr. Al-Khair Sayed Beshir of Dhofar Municipality and Salah Ageib, The General Directorate of Agriculture, Fisheries and Animal Wealth, Oman). The following numbers of animals slaughtered in slaughterhouses in the Dhofar region over the years 2007 to 2010 is self-explanatory.

Table 2. The cost of camel feeding per month (Camel owner 3).

\begin{tabular}{llcc}
\hline $\begin{array}{l}\text { No. of } \\
\text { Camels }\end{array}$ & Item & $\begin{array}{c}\text { Cost per Month } \\
\text { (in Omani Riyal) }\end{array}$ & $\begin{array}{c}\text { Equivalent } \\
\text { (in US \$) }\end{array}$ \\
\hline 50 & $\begin{array}{l}\text { Commercial fodder } \\
\text { (hashish) } \\
\text { Camel food } \\
\text { (concentrates) }\end{array}$ & ca. 600 & ca.1554 \\
\hline Total & ca. 450 & ca. 1165 \\
\hline
\end{tabular}


Table 3. Rate of camels slaughtered in Salalah slaughterhouse.

\begin{tabular}{lcccc}
\hline Animal & $\begin{array}{c}\text { Year } \\
2008\end{array}$ & $\begin{array}{c}\text { Percentage } \\
(\%)\end{array}$ & $\begin{array}{c}\text { Year } \\
2009\end{array}$ & $\begin{array}{c}\text { Percentage } \\
(\%)\end{array}$ \\
\hline Camels & 4008 & 24.2 & 2728 & 16.4 \\
Cattle & 12521 & 75.8 & 13903 & 83.6 \\
\hline Total & 16529 & 100 & 16631 & 100 \\
\hline
\end{tabular}

As claimed by all camel pastoralists interviewed in the field: "We spend more on our camels than what they give us back." Said Mohamed bin Kashoub, an elderly camel owner states that a camel owner today needs another source of income to sustain his camels. Indeed, Dhofari camel pastoralists claim that keeping their animals is becoming extremely expensive. However, this economic tolerance which makes pastoralists keep their animals in spite of the obvious economic impediment, rests on an inherited cultural obsession. Salm Al Shahri a young camel pastoralist, gives the following account of his experience with his camels:

"When I watch the camels grazing in the wadi, I cry to them

"doe, doe" (in Jabali means eat, eat).

I feel good and comfortable."

These pastoralists in fact find their comfort in their camels. This strong belief and infatuation has evolved in the passage of time with camel pastoralism. It seems to have evolved in response to the fact that camels were the means of survival, capital and wealth in an adaptation that survived harsh and arid environmental conditions. Worldwide, camels among pastoralists are a symbolic culture of pride and status. It is an ancient cultural obsession, which is well illustrated by one camel owner, who stated it genuinely by saying: "My family can spend the night without food, but not my camels."

However, at this time economic revenue from camels in Dhofar is extremely poor. It can be summed up by the following:

- Male calves are sold at the age of six months to one year. A considerable number of these calves are sold to be transported to the United Arab Emirates. It seems the Emirates present a good and a potential market for camels.

-Numbers of camels slaughtered for meat is poor as indicated by the statistics above. Camels are also occasionally sold for social events such as marriage, etc.

-The cost of camel meat in the Salalah's market is three riyal Omani per kilogram (ca 7.8 US dollars). This price is high when compared with the price of other imported meat.

-Milk has no market in Dhofar or in other parts of the Sultanate. It is not part of the urban local food items. On the contrary, it is not marketed at all. This situation remains unaddressed and not probably investigated.

Consequently, the current market for camel products in Dhofar is very limited. Significantly, under the current situation its future prospects are clearly uncertain.

\section{Space and Land Value}

Change for the camel pastoralists is inevitable. They cannot avoid it. Their old ways and adaptation are now confronted with the changing space around them. One aspect of the changing space are the new laws that address the land and its natural resources. This is clearly manifested by "the law of pasture and the management of animal wealth 2003" (1) and "the executive plan issued by the Ministry of Agriculture and Fisheries" (2). This

Table 4. Rate of camels slaughtered in Taga slaughterhouse.

\begin{tabular}{|c|c|c|c|c|c|c|c|c|}
\hline Animal & $\begin{array}{l}\text { Year } \\
2007\end{array}$ & $\begin{array}{c}\text { Percentage } \\
(\%)\end{array}$ & $\begin{array}{l}\text { Year } \\
2008\end{array}$ & $\begin{array}{c}\text { Percentage } \\
(\%)\end{array}$ & $\begin{array}{l}\text { Year } \\
2009\end{array}$ & $\begin{array}{c}\text { Percentage } \\
(\%)\end{array}$ & $\begin{array}{l}\text { Year } \\
2010\end{array}$ & $\begin{array}{c}\text { Percentage } \\
(\%)\end{array}$ \\
\hline Camels & 384 & 13.3 & 356 & 11.9 & 318 & 9.7 & 334 & 12.2 \\
\hline Cattle & 1576 & 54.7 & 1559 & 52.2 & 2012 & 61.6 & 1565 & 57.1 \\
\hline Goat/Sheep & 920 & 31.9 & 1069 & 35.8 & 939 & 28.7 & 843 & 30.7 \\
\hline Total & 2880 & 100 & 2984 & 100 & 3265 & 100 & 2742 & 100 \\
\hline
\end{tabular}

Table 5. Rate of camels slaughtered in Mirbat slaughterhouse.

\begin{tabular}{lcccc}
\hline Animal & $\begin{array}{r}\text { Year } \\
2008\end{array}$ & $\begin{array}{c}\text { Percentage } \\
(\%)\end{array}$ & $\begin{array}{c}\text { Year } \\
2009\end{array}$ & $\begin{array}{c}\text { Percentage } \\
(\%)\end{array}$ \\
\hline Camels & 288 & 36 & 277 & 32 \\
Cattle & 509 & 64 & 589 & 68 \\
\hline Total & 797 & 100 & 866 & 100 \\
\hline
\end{tabular}

Table 6. Rate of camels slaughtered in Sadah slaughterhouse.

\begin{tabular}{lcccc}
\hline Animal & $\begin{array}{c}\text { Year } \\
2008\end{array}$ & $\begin{array}{c}\text { Percentage } \\
(\%)\end{array}$ & $\begin{array}{c}\text { Year } \\
2009\end{array}$ & $\begin{array}{c}\text { Percentage } \\
(\%)\end{array}$ \\
\hline Camels & 263 & 58.3 & 316 & 56.3 \\
Cattle & 188 & 41.7 & 245 & 43.7 \\
\hline Total & 451 & 100 & 561 & 100 \\
\hline
\end{tabular}




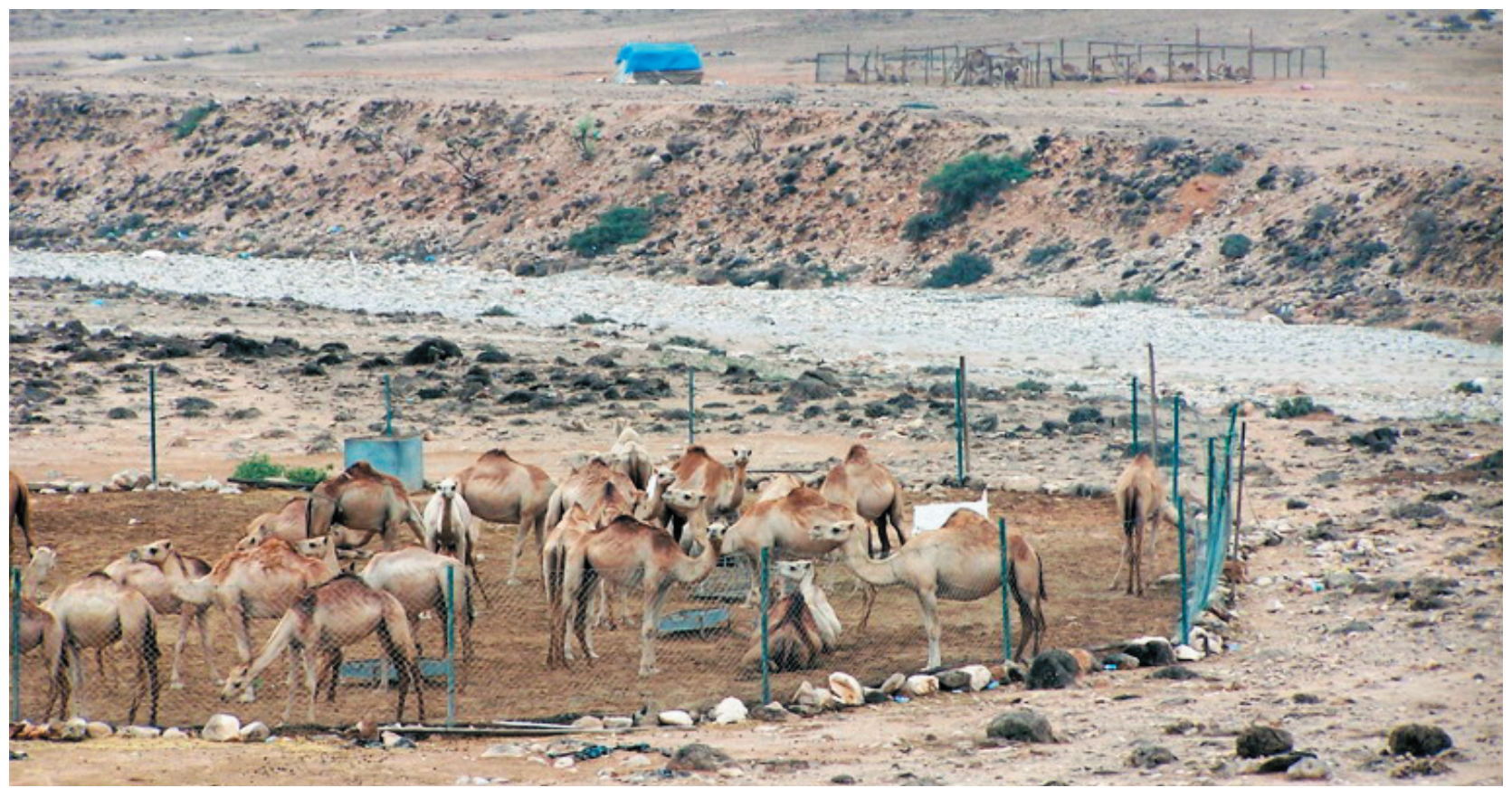

Plate 6. Camels inside enclosures.

law organizes the use of pasture as one component of the natural resources. Equally, the same law addresses the number of animals in the region in relation to the pastures' carrying capacity. Article (14) of the $2^{\text {nd }}$ chapter of the executive plan issued by the Ministry of Agriculture and Fisheries of this law (2) states the following:

"Every owner, whose animals exceed the natural pastures'carrying capacity in Governate or in the area, is obliged to reduce the numbers of animals or keep his animals in enclosures. The enclosures must be approved by the concerned authorities."

Camel owners are now compelled to keep their animals in enclosures (Plates 4, 6 and 7). Their transhumant seasonal movement is no longer as free as they wish. First, they cannot camp seasonally as they wish. Now land is state property and not tribal. Second, the pastoralists themselves are now inclined to settle in a gradual manner.

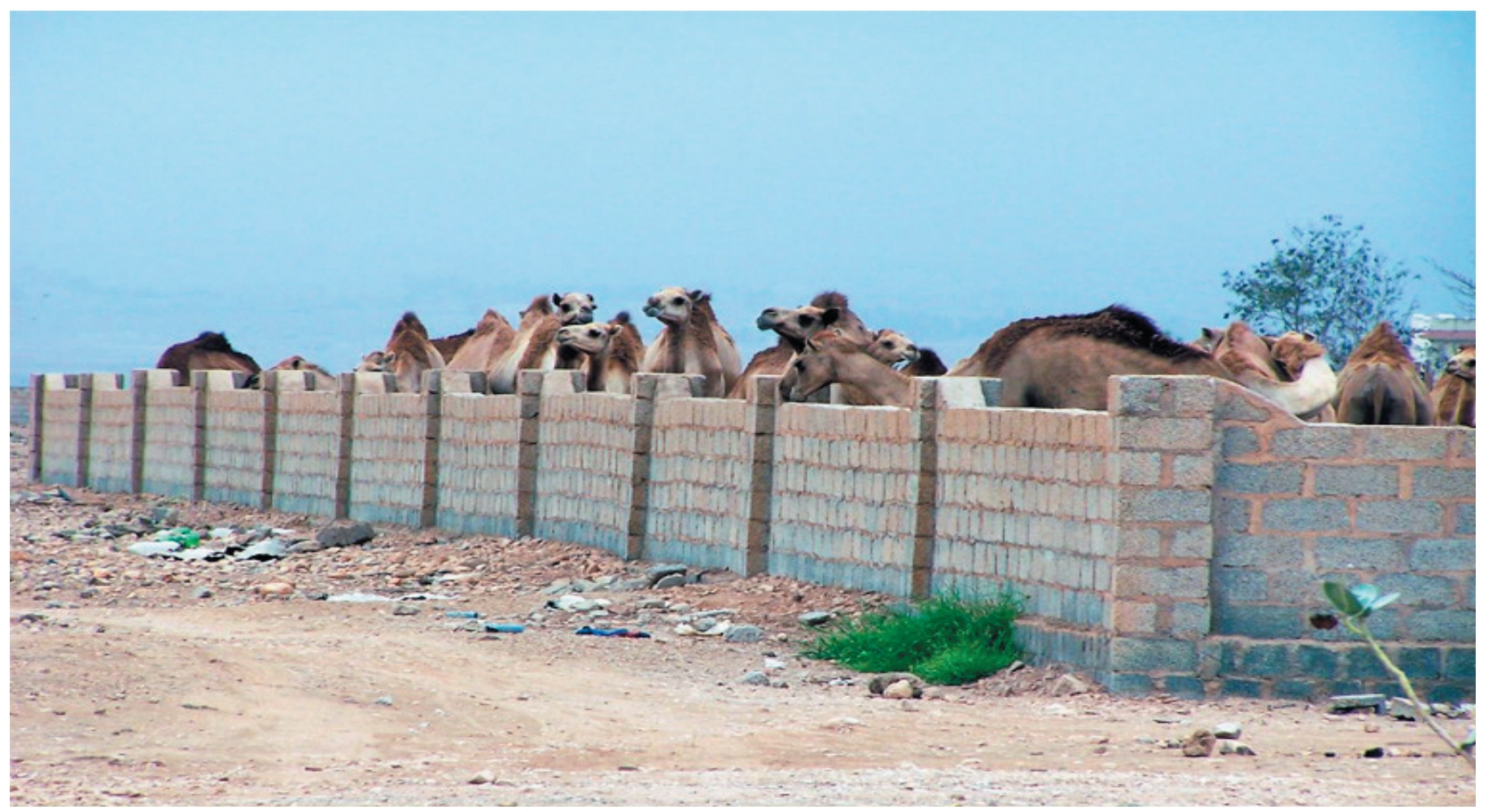

Plate 7. Free grazing is restricted. 


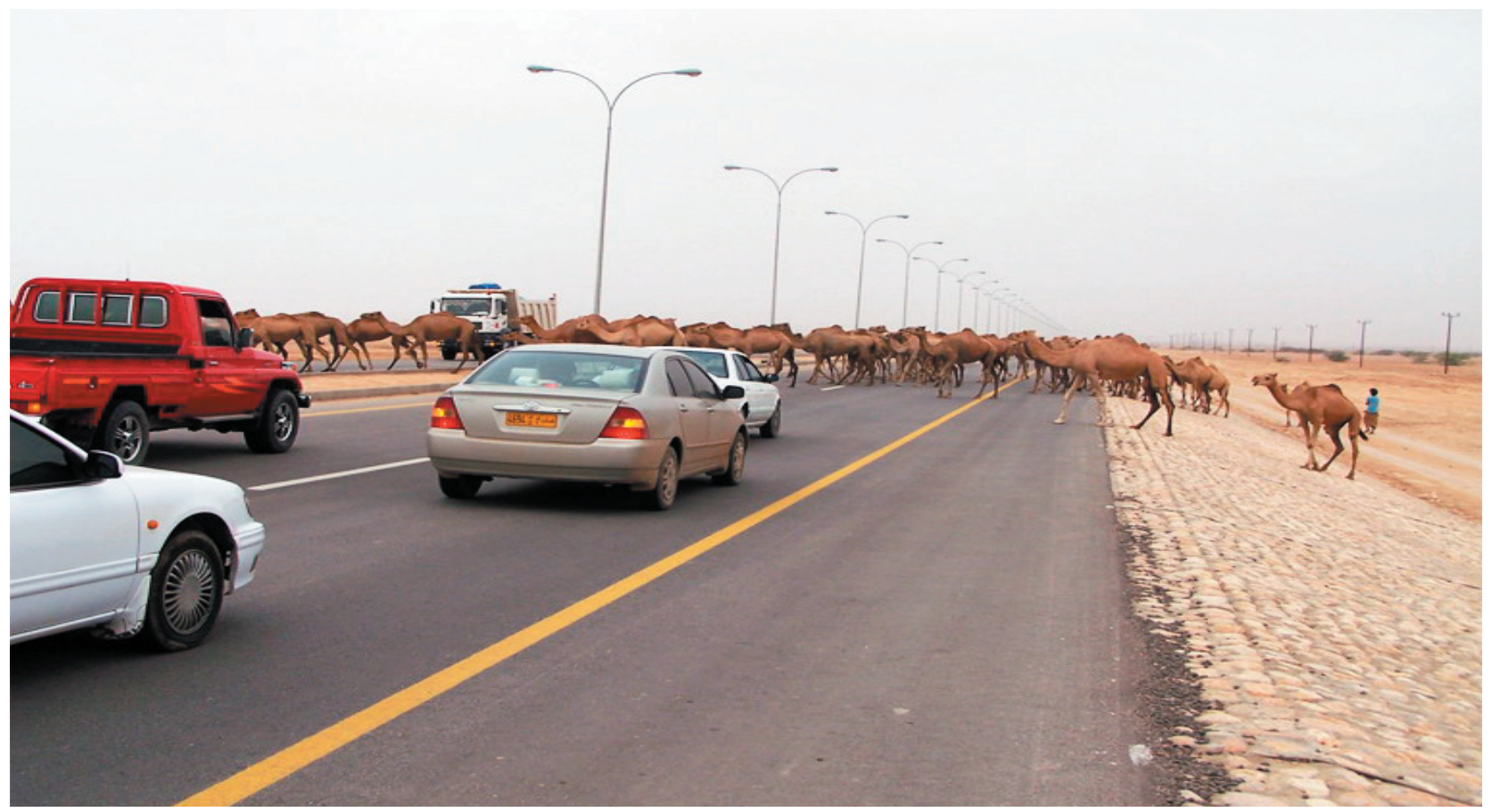

Plate 8. Motor roads and camels are obstacles and hazard.

At present, land value in Dhofar is too expensive to be invested in traditional camel nomadic pastoralism. Development has enhanced the value of land and dramatically increased its worth. Land is to be invested in tourism, habilitation plans, roads, etc. Like everywhere in the world, Dhofari camel nomadic pastoralism has no place in this new space.

Space for camel nomadic pastoralism is the most vital component in its endurance and attainment. Movement for camel pastoralists in Dhofar is important in order to exploit natural resources over a large area and to avoid the possible hazards and disturbance of hematophagous flies (ElMahi, 2010; ElMahi, 2011b). The movement of the camel pastoralists is geared towards the various seasons of the year. In the rainy seasons, they move away from the rain zone since camels do not tolerate wet conditions and can easily sleep in muddy terrain. In this process, different families meet and interact with each other. Indeed, sitting and talking to camels pastoralists, one can easily feel their sensation and the jubilation they collectively gain from the seasonal movement. Again, in this social interaction they exchange knowledge and the outcome of their experience.

Therefore, space is a vital element in nomadic pastoralism. Space is essential for open grazing and animal movements. Given the current conditions of pasture (Ageib, 1996, unpublished report) it becomes obvious that camels need to cover larger areas for pasturing. Furthermore, this type of grazing is a low cost animal husbandry, where the animals are dependent on the available natural resources. And the mechanism of this low cost undertaking is the open grazing and pastoral movements.
Space for camel pastoralists and goat herders in Dhofar is demarcated by the local tribal arrangements where land and pasture are divided in "haram." This type of organizing space manifests an ancient ranking of land as a tribal territorial space. By this tribal arrangement, each family or household moves freely within these tribal territories and their animals graze in a well-defined area (ElMahi, 2011).

The present development process brings a serious challenge to nomadic camel pastoralism in the Dhofar region. It is the issue of space that challenges this old way. Therefore, any change in a pastoral group's physical space can have far-reaching consequences. Some of these consequences are explainable, others are inexplicable. As a result of the progressive development land value has changed dramatically in response to the tourism industry and enterprises in the Dhofar region. Considerable land has been designated to touristic resorts. Consequently, areas which were used traditionally by camel pastoralist have either been taken or dissected by these projects or motor roads and highways (Plate 8). Accordingly, land and space for grazing and mobility has become too expensive to be invested in camel nomadic pastoralism and hence, pastoralists are gradually deprived of the extended space they have exploited from as far back as they remember.

Another challenge to camel pastoralists is not only the lack of space, but also the changing space around them. Camels are now endangered by motor cars and endangering passengers in motor cars. Guided by their owners, camels cross highways at least twice a day. Their owners without any hesitation obstruct the moving vehicles by running in front of them (Plate 9). The authorities in Dhofar have 


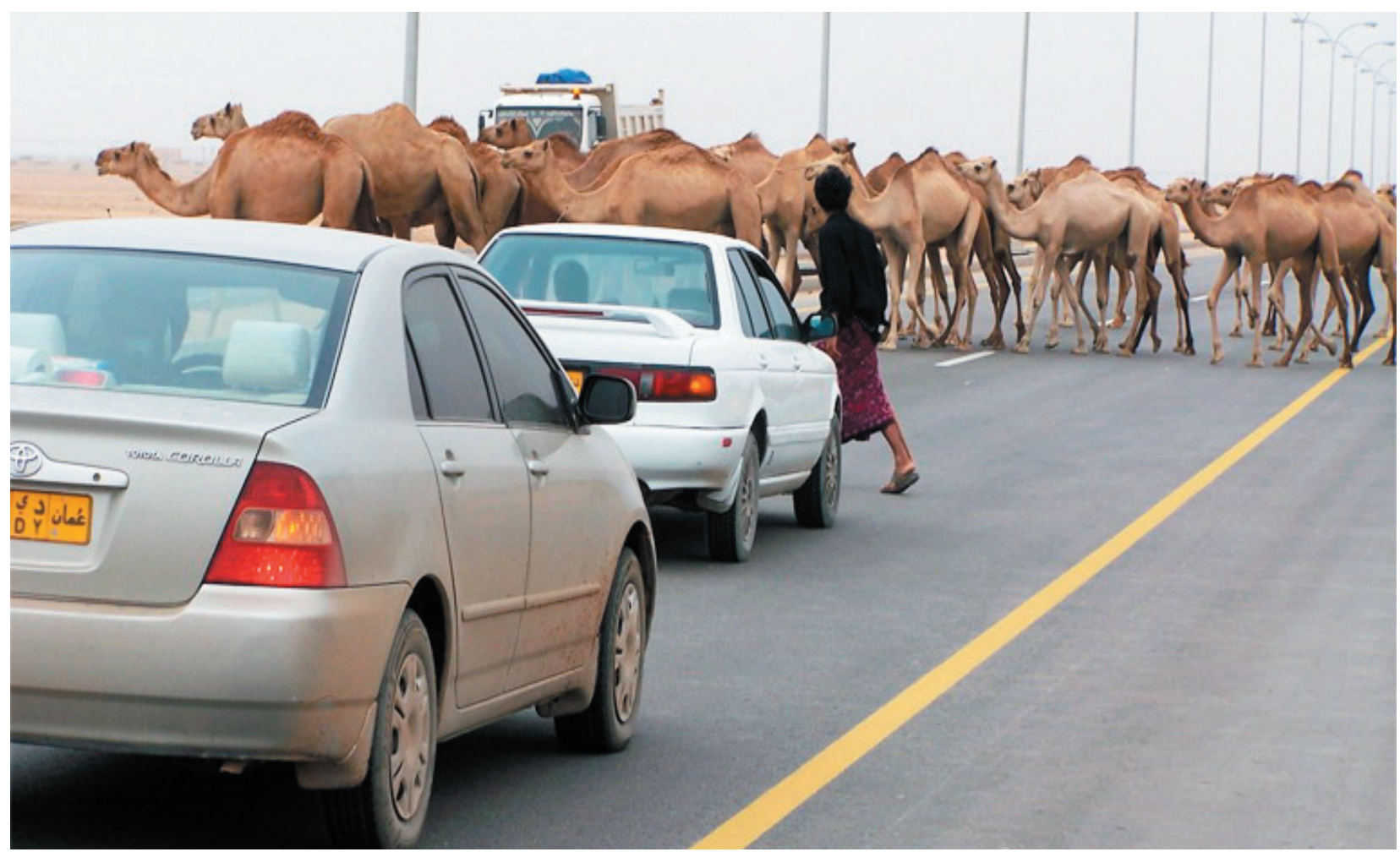

Plate 9. A camel owner hinders vehicles to shield his animals.

asked camel owners to keep their animals in enclosures, according to the camel herders.

Development in any location is known to have consequences. The outcome can be positive or negative on certain aspects. In some countries development can have a negative effect on certain environmental components such as wildlife or the flora. The effect can vary in nature, character and magnitude. In the Dhofar region, a consequence is the loss of a national wealth: camels. This national wealth can be reduced dramatically with the passage of time. The present generation that is keeping this national wealth will not last forever. Another generation of young Dhofaris with modern education is expected to undertake the responsibility for sustaining this national wealth. This generation is not prepared to follow the footsteps of their ancestors when it comes to camel pastoralism in Dhofar. Modern education has made them indifferent to traditional professions. Moreover, this profession is no longer profitable enough to attract younger generations.

\section{Camel Future Perspectives in Dhofar}

Today, the global situation of food is raising questions about worldwide food security. In fact, the situation is seriously alarming. It is estimated now that around one billion people are suffering from hunger and malnutrition. Among the urgent global priorities is how to combat this acute situation. Federal Minister of Food, IlseAigner, (the European Parliament) (cf.http://www.bmelv.de/EN/
European-International Affairs/Global-Food-Situation-FAO/ global-food-situation-FAO-node.html) has clearly identified the situation with the following word of caution:

\section{"Achieving global food security is one of the greatest challenges of our time."}

On the other hand, Rosegrant et al. (2001) addresses the global food supply situation up to 2020 through the findings of the International Food Policy Research Institute. Given the climatic change, life style, technology and changes in global policy, the work of Rosegrant et al. (2001) portrays an unpropitious picture for the future global food situation.

The global food supply situation necessitates urgent united global efforts in which every country has a share of responsibility and obligation. Again, food shortages are not sudden events, but occur almost imperceptibly. Experience has taught us that famines take place by almost indiscernible degrees and develop little by little, not sharply or suddenly.

Therefore, the Sultanate of Oman has a national and a global responsibility to invest in this national wealth. Proper investment in camels and their products can create a highlyprized contribution by the Sultanate of Oman in opposing one of the most significant challenges of this century.

Not far away from Dhofar, the United Arab Emirates present an interesting and profitable approach to camel products. The literature was explored for scientific 
papers that address the camel issue and investment in the Emirates. In fact, the only source for information available is the newspapers in the Emirates which report that Dubai Emirate is taking the lead in economic investment by handling its camel wealth in the following manner:

Marketing camel milk. Camel milk with different flavors is sold in grocery stores.

Meat is well marketed. There is a factory specialized in making camel milk into powder milk. It should be noticed that fat percentage in camel milk is $3.8 \%$. Chocolate made with camel milk is well marketed in the United Arab Emirates.

The latest news comes from Al-Watan Omani Newspaper (2010). The translation of the news reads as follows:

"Dubai (DBA) the government of the United Arab

Emirates is making preparations to export camel milk to European states next year after the approval of the European commission of the safety procedures for the milk to be imported from the Emirate state."

Furthermore, Al Bayan Arabic Newspaper (UAE) (1.9.2006) reported that the United Arab Emirates factory for the production of camel milk and derivatives in Dubai produces "camelicious" camel milk and distributes it to the local markets in the country. Behind this production there are extended research efforts carried out by the "Research Laboratory of Veterinary Medicine Central."

Another interesting news story that shows how camel milk is used in other countries was reported by Al Bayan Arabic Newspaper paper (11.11.2006). It reported that an Indian company has introduced the first ice-cream made from camel milk.

Again, on May 3, 2010, Al Bayan Newspaper presented a headline that says "Camel burgers attract tourists in Dubai." Now tourists in Bastakiya historical area (Dubai) enjoy the good taste of camel-meat burgers.

Once more, Al Bayan Newspaper (6.10.2010, issue 1167) reports an interesting headline: "UAE the world's most advanced in the breeding of camels." The Newspaper gives more details about a camel hybridization technique in the UAE, including the transfer of embryos and cloning, in order to produce new breeds of camels. Moreover, cross breeding is designed for commercial and research objectives.

These news items clearly indicate the potential of camel products. But then, what is the solution? Is it affordable to watch a national asset decline and fade away in such changing global conditions? This will be a fatal mistake. The issue of camel husbandry needs a different approach and a broader scope of understanding the accurate implications and benefits involved. What is required is that the Government authorities in Oman and in Dhofar organize the following delineated procedures:
The formation of a committee of specialized individuals.

An extensive pilot study to explore the whole issue of camels husbandry and its potential in the Dhofar region. The study should propose a careful well-researched strategy.

The first principle this strategy should adopt is that both camels and the flora in Dhofar are to be conserved. It should argue that camels are not an impediment to the development of the region. It is crucial that camels should not be regarded as a problem, but as a significant viable economic asset. Camels are a viable national asset that needs to be developed and invested in.

The needed strategy should not in any case be a policy of culling. Culling the herds is a transitory policy that serves short term goals. Camel numbers are reduced for a short period of time before the herds increase in numbers again. This is an impermanent solution. Such a policy in the long run does not serve any investment in camels. On the contrary, the strategy should encourage camel owners to increase their herds and at the same time they should focus on their quality. This must not be at the cost of natural pasture. Natural pasture should be preserved and well managed. The strategy must call for the contribution of energy, time and activities in an undertaking of potential benefit for all starting from the camel owner. This leads to a shift from camel pastoralism to camel farming.

The success of any project to deal with camel milk in Dhofar will require a definite means to collect milk from camel owners. This issue has to be sufficiently studied, and the possibility of fixed points for the gathering and collecting of milk has to be adequately studied.

In reality, the camel issue has many facets, and many parties are involved and have an interest in it. The Government of Dhofar, the camel owners and the private sector (e.g. animal feed industry) collectively have an interest in this issue. Therefore, any policy to address camels should engage all members involved. The participation of more than one party should be geared towards a policy of increasing animal numbers rather than reducing it. It should be a policy that explores the various possibilities to invest in the Dhofari camels. Milk and camel meat should be the focus for an extensive investment and marketing policy. Such domestic and international policies are to be adopted by the concerned government sectors and the private sector. International and local investments are to be attracted and motivated. Different government bodies have significant roles to play in this respect. They are to facilitate all procedures for domestic and international investors in Dhofar. Such a visionary camel project is an enterprise that offers the possibility of profit and conserves an ancient national asset.

Camels in Dhofar are a national asset which deserve adequate attention for a substantial development and serious participation in facing the global food shortage. 
If this wealth is adequately managed, it can potentially contribute to the development of the whole region. Hence, within a context of such a changing space, Dhofar needs new development strategies to replace the old ones.

\section{Acknowledgements}

The author is indebted to Sultan Qaboos University for supporting the research project (Traditional Camel Management in Dhofar. Project No: (ART/ARCH/09/01). The financial and logistical support is invaluable.

Nasser Al-Hinai (Sultan Qaboos University) made the maps. As always, he is an invaluable field assistant. Salah Ageib (Ministry of Agriculture, Dhofar), Salm Al-Shahri (Sultan Qaboos University), Yassir Al-Rufai, Dr. AlKhair Sayed Beshir (Dhofar Municipality) helped greatly. In Dhofar, all the camel pastoralists were hospitable and generous. To all of them, the author is indebted.

\section{References}

Abbas, B., N. Chabeuf, G. Saint-Martin, P. Bonnet, A. Millaird, H. Beshir, and B. Musa. 1992. Camel pastoralism in the Butana and northeastern Sudan: an interdisciplinary study. Nomadic Peoples 31:64-84.

Abdullahi, A.M. 1990. Pastoral Production Systems in Africa: A Study of Nomadic Household Economy and Livestock Marketing in Central Somalia. In: Farming Systems and Resource Economics in the Tropics. Vauk Wissenschaftsverlag, Kiel Germany. 256 pp.

Al-Bayan Arabic Newspaper. 2006 \& 2010. http: //www.albayan.ae

Ageib, S.M.A. 1997. A study of the spread of Prosopis species in the plain of Dhofar. Unpublished report in Arabic. The Ministry of Agriculture and Fisheries. Salalah, Sultanate of Oman.

Al-Watan Arabic Newspaper. 2010. Business. Vol. 40, No. 9834, p. 12, July 5, 2010.

Barfield, T.J. 1993. The Nomadic Alternative. Prentice Hall, Englewood Cliffs, N.J.

Beck, L. 1998. Use of Land by Nomadic Pastoralists in Iran: 1970-1998. In: Transformation of Middle Eastern Natural Environment, Yale F\&Es Bulletin, 103:58-80.

Birks, S. 1978. The mountain pastoralists of the Sultanate of Oman reactions to drought. Development and Change 9:71-86.

Brey, F. and B. Faye. 2005. The camel and society. In: Desertification Combat and Food Safety: The Added Value of Camel Producers, Bernard Faye and Palmated Esenow (Editors), 23-30. Series 1: Life and Behavioural Science. Vol. 362. IOS Press.

Chatty, D. 1990. Tradition and Change among Pastoral Harasiis in Oman. In: Anthropology and Development in North Africa and the Middle East, M. SalemMurdock, and M. Horowitz (Editors), 336-349. Westview Press, Boulder, Colorado.
Chatty, D., M. Zaroug, and A. Osman. 1991. Pastoralists in Oman. Rome: Food and Agriculture Organization, Copenhagen. Folk 14-15:27.

Chatty, D. 1994. Petroleum Exploitation and the Displacement of Pastoral Nomadic Households in the Sultanate of Oman. In: Population Displacement and Resettlement: Development and Conflict in the Middl East, Seteney Shami, (Editor), 89-106. Center for Migration Studies, New York.

Chatty, D. 1996. Mobile Pastoralists: Development Planning and Social Change in Oman. Columbia University Press, New York. 230pp.

Chatty, D. 2002. Adapting to Multinational Oil Exploration: the Mobile Pastoralists of Oman. In: Mitteilungen des SFB Differenz und Integration: Nomadismus aus der Perspektiveder Begrifflichkeit, Stefan Leder and Bernhard Streck (Editors), 2:1-19. Centre for Oriental Studies (OWZ), Martin Luther University of Halle-Wittenberg.

Dyson-Hudson, R. and N. Dyson-Hudson. 1980. Nomadic pastoralism. Annual Review of Anthropology 9:15-61.

ElMahi, A.T. 2010. Pastoralists adjustment to hematophagous flies in Dhofar: An analogy of an ancient adaptation. Adumatu 21:15-32.

ElMahi, A.T. 2011. Traditional goat management in Dhofar and the desert, Oman: an ethnoarchaeological study. Sultan Qaboos University, Sultanate of Oman.

ElMahi, A.T. 2011b. Hematophagous flies in Dhofar, Oman: A limiting factor and a potential pathogenic vector. Sultan Qaboos University Agricultural and Marine Sciences - A Research Journal 11:15-23.

Gauthier-Pilters, H. and A.I. Dagg. 1981. The Camel, its Evolution, Ecology, Behavior and Relationship to Man. University of Chicago Press, Chicago.

Gilbert, A. 1983. On the origins of specialized nomadic pastoralism in western Iran. World Archaeology 15: 105-19.

Global Food Situation and FAO. http://www.bmely.de/ EN/European-InternationalAffairs/Global-FoodSituation-FAO/global-food-situation-FAO_node.html.

Hüelsebusch, C.G. and B.A. Kaufmann. 2002. Camel Breeds and Breeding in Northern Kenya - An Account of Local Camel Breeds of Northern Kenya and Camel Breeding Management of Turkana, Rendille, Gabra and Somali Pastoralists. Kenya Agricultural Research Institute, Nairobi, Kenya, pp. 65-90.

Ibrahim, F.N. 1978. The Problem of Desertification in the Sudan with Special Reference to Northern Darfur Province. Development Studies and Research Centre Monograph. Series No. 8. University of Khartoum, Khartoum.

Kakar, A.R., K. Verdier, and M. Younas. 2011. Rapid change of strategy is necessary for development of dromedary camel pastoralism in the Cholistan desert of Pakistan. Pastoralism, Research, Policy and Practice 1:1-9. 
Kaufmann B.A. and C. Binder. 2002. Production Aims and Functions of Camels in Kenyan Pastoral Systems. In: Camel Breeds and Breeding in Northern Kenya, An Account of Local Camel Breeds of Northern Kenya and Camel Breeding Management of Turkana, Rendille, Gabra and Somali Pastoralists. C.G. Hulsebusch and B.A. Kaufmann (Editors), 15-28. Kenyan Agricultural Institute (KARI), Nairobi, Kenya.

Köhler-Rollefson, I. 2003. Community-based management of animal genetic resources - with special references to pastoralists. In: Proceedings of the Workshop on Community-Based Management of Animal Genetic Resources. pp. 14-26. Mbabane, Swaziland, 7-11 May, 2001.

Köhler-Rollefson, I., B.E. Musa, and M. Fadl Achmed. 1991. The camel pastoral system of the southern Rashaida in eastern Sudan. Nomadic Peoples p. 29.

Ministry of Agriculture and Fisheries (MAF). 2005. Agricultural Census 2004/2005 Batinah Region. Vol. 3. Ministry of Agriculture and Fisheries, Directorate General of Planning and Investment Production, Department of Statistics and Information.

Odum, E.P. 1971. Fundamentals of Ecology. W.B. Saunders Company, London.
Rosegrant, M.W., M.S. Paisner, S. Meijer, and J. Witcover. 2001. Global Food Projections to 2020: Emerging Trends and Alternative Futures. International Food Policy Research Institute, Washington, DC 200061002, USA.

Salih, M. 1988. Camel reproduction in the arid lands of the Sudan: National and local perceptions of the potential. In: Camels in Development, pp. 19-29. Scandinavian Institute of African Studies, Stockholm.

Shepherd, A. 1983. Capitalist agriculture in the Sudan. Development and Change 14:297-321.

Sperling, L. 1987 The adoption of camels by Samburu cattle herders. Nomadic Peoples 23:1-18.

Spooner, B. 1975. The Cultural Ecology of Pastoral Nomads. An Addison-Wesley Module in Anthropology. No. 45, 53 pp.

Tefera, M. and F. Gebreah. 2001 A study on the productivity and diseases of camels in eastern Ethiopia. Tropical Animal Health and Production 33:265-274.

Zarins, J. 1989. Pastoralism in southwest Asia: the second millennium BC. In: The Walking Larder. J. Clutton-Brock (Editor), 127-1551. Unwin Hyman, London.

Received: October 20, 2010

Accepted: September 25, 2011 